\title{
Associations of body mass index and diabetes with hip fracture risk: a nationwide cohort study
}

\author{
Hsiu-Ling Huang ${ }^{1,2+}$, Cheng-Chin Pan ${ }^{3 \dagger}$, Yu-Fen Hsiao ${ }^{1}$, Ming-Chih Chen ${ }^{4}$, Chuan-Yu Kung ${ }^{5}$, Pei-Tseng Kung ${ }^{6,7}$
} and Wen-Chen Tsai ${ }^{2 *}$

\begin{abstract}
Background: The high prevalence of diabetes is associated with body mass index (BMI), and diabetes can cause many complications, such as hip fractures. This study investigated the effects of BMI and diabetes on the risk of hip fractures and related factors.

Methods: We retrospectively reviewed data from 22,048 subjects aged $\geqq 40$ years from the National Health Interview Survey in Taiwan (NHIST) in 2001, 2005, and 2009. We linked the NHIST data for individual participants with the National Health Insurance Research Database (NHIRD), which includes the incidence of hip fracture from 2000 to 2013. We defined five categories for BMI: low BMI (BMI< 18.5), normal BMI (18.5 BMI < 24), overweight $(24 \leqq \mathrm{BMI}<27)$, mild obesity $(27 \leqq \mathrm{BMI}<30)$, and moderate obesity $(\mathrm{BMI} \geqq 30)$. The Cox proportional hazards model was used to analyze the effects of BMI and diabetes on risk of hip fracture.

Results: The Cox proportional hazards model shows that hip fracture risk in participants with diabetes was 1.64 times that of non-diabetes patients (95\% confidence interval [CI]:1.30-2.15). Participants with low BMls showed a higher hip fracture risk (HR: 1.75) than those with normal BMI. Among the five BMl groups, compared with nondiabetes patients, only diabetes patients with a normal BMI showed a significantly higher risk on hip fracture (HR: 2.13, 95\% Cl: 1.48-3.06). In participants with diabetes, compared with those with normal BMI, those with overweight or obesity showed significantly lower hip fracture risks (HR: 0.49 or 0.42 ). The hip fracture risk in participants who expend $\geqq 500 \mathrm{kcal} /$ week in exercise was 0.67 times lower than in those who did not exercise.
\end{abstract}

Conclusions: Diabetes and low BMI separately are important risk factors for hip fracture. There was an interaction between diabetes and BMI in the relationship with hip fracture $(p=0.001)$. The addition of energy expenditure through exercise could effectively decrease hip fracture risk, regardless of whether the participants have diabetes or not. The results of this study could be used as a reference for health promotion measures for people with diabetes.

Keywords: BMI, Body mass index, Hip fracture, Diabetes, National Health Insurance

\section{Background}

The worldwide incidence of hip fracture is predicted to increase from 1.66 million as of 1990 to 6.26 million by 2050 [1]. The global population is ageing, and hip fractures significantly affect the mobility and mortality of the elderly. The associated medical costs should also not

\footnotetext{
* Correspondence: wtsai@mail.cmu.edu.tw

${ }^{+}$Hsiu-Ling Huang and Cheng-Chin Pan contributed equally to this work.

${ }^{2}$ Department of Health Services Administration, China Medical University, 91,

Hsueh-Shih Road, Taichung 40402, Taiwan, Republic of China

Full list of author information is available at the end of the article
}

be overlooked [2,3]. Both type 1 and type 2 diabetes can increase hip fracture risk and complications due to abnormal bone metabolism $[4,5]$. Vestergaard found that compared with those without diabetes, the relative risk (RR) for hip fractures in patients with type 1 diabetes was 6.94, and that for hip fractures in patients with type 2 diabetes was 1.38 [6]. In other studies, patients with longer diabetes duration were associated with a higher hip fracture risk compared to patients without diabetes. When the diabetes duration was $<5$ years, RR was 1.8 , but when the diabetes duration was $>15$ years, RR

(c) The Author(s). 2018 Open Access This article is distributed under the terms of the Creative Commons Attribution 4.0 International License (http://creativecommons.org/licenses/by/4.0/), which permits unrestricted use, distribution, and reproduction in any medium, provided you give appropriate credit to the original author(s) and the source, provide a link to the Creative Commons license, and indicate if changes were made. The Creative Commons Public Domain Dedication waiver (http://creativecommons.org/publicdomain/zero/1.0/) applies to the data made available in this article, unless otherwise stated. 
increased to $2.66[7,8]$. According to previous studies, diabetes was positively associated with risk of hip fracture.

The high prevalence of diabetes is related to population ageing and body mass index (BMI, unit: $\mathrm{kg} / \mathrm{m}^{2}$ ). The World Health Organization (WHO) recommends using BMI as an important indicator of obesity [9]; the higher the BMI, the higher a patient's risk is for metabolic diseases [10]. Being either overweight or obese can increase the incidence of type 2 diabetes, and the incidence of diabetes in obese adults is approximately 3-7 times that of adults with normal weight. The incidence in those with a BMI of $>35$ is 20 times that in those with BMIs of 18.5-24.9 [11, 12].

To understand, a higher BMI level was associated with a higher prevalence of type 2 diabetes, and diabetes is an important risk facture for hip fracture. In addition to BMI and diabetes, the study from Søgaard et al. found that risk of hip fracture decreased with increasing BMI [13]. De Laet et al. [14] also found that people with a BMI of $30 \mathrm{~kg} / \mathrm{m}^{2}$ showed a lower hip fracture risk (RR: 0.83; 95\% confidence interval [CI]: 0.69-0.99) than those with a BMI of $25 \mathrm{~kg} / \mathrm{m}^{2}$. BMI is associated with the incidence of fracture. Aurégan et al. [15] suggest that low $\mathrm{BMI}$ independently increase the risk of fractures. Johansson et al. [16] also found that low BMI was a risk factor for hip and all osteoporotic fracture. However, another study found that among postmenopausal women, obese women showed a higher risk of ankle and upper leg fractures than nonobese women [17]. Thus, low BMI is an important risk factor for fractures, but the relation between high BMI and fractures is not clear [16, 17].

Obesity is one of the major risk factors for type 2 diabetes, which may in turn also increase hip fracture risk. However, it is still uncertain whether BMI has an impact on hip fractures in diabetes patients. Thus, we investigated whether diabetes has same effects on risk of hip fracture in those with different BMI, and the effects of BMI on hip fracture risk in diabetes patients.

\section{Methods}

\section{Data sources and participants}

We retrospectively reviewed quadrennial data from the National Health Interview Survey in Taiwan (NHIST) for the years 2001, 2005, and 2009. The survey participants' height and weight data were used to calculate the baseline BMI. We excluded pregnant women and participants younger than 40 years. We linked the NHIST participants' individual data with the National Health Insurance Research Database (NHIRD), which includes nationwide data on all citizens in Taiwan. We extended the washout period to January 1st, 2000 for our participants in this study. All participants who had been diagnosed with hip fracture before NHIST survey were excluded from this study to make sure the temporal relationship between $\mathrm{BMI} /$ diabetes and hip fracture. We included a total of 22,048 participants and monitored hip fracture incidence for the period of 2000 to 2013.

The NHIST was conducted nationally and quadrennially by the Taiwan Health Promotion Administration. The information available from surveys include personal information, personal health status, knowledge about disease prevention, utilization of medical services, personal health behaviour, self-rated health status, and work and economic status, among others. The survey results provide a reference for developing and implementing healthcare policies in Taiwan [18].

This study was reviewed and approved by the research ethics committees of China Medical University (IRB No.: CMUH 103-REC3-109). We deleted all personal identification from the data analysed in this study to protect the patients' personal identities. Taiwan's National Health Insurance program was launched in March 1995, and as of 2013, the nationwide coverage rate was $99.68 \%$ [19]. This compulsory public health insurance program provides comprehensive information such as demographic data and data on all medical services, including prescription drugs, surgical treatments for outpatients, emergency care, and inpatient care. The NHIRD includes medical information on all citizens covered by insurance, including treatments for diabetes, hip fractures, and other conditions [20, 21]. The comprehensiveness and accuracy of the NHIRD have been confirmed by the Ministry of Health and Welfare, and the database has been used in numerous studies $[22,23]$.

\section{Variable descriptions}

The variables examined were BMI, personal basic characteristics (sex, age), environmental factors (urban or rural residential areas), socio-economic status (monthly salary), health status (Charlson Comorbidity Index [CCI] and diabetes complication severity index [DCSI]), health behaviour (weekly energy expenditure through exercise), and diabetes status. The WHO has developed a classification of BMI for international use, but the index for overweight Asian adults is lower than the world average. Thus, many Asian countries have developed their own criteria for overweight and obesity. We used the BMI classification criteria of the Taiwan Health Promotion Administration and divided the participants into five categories: low BMI (BMI < 18.5), normal BMI $(18.5 \leqq \mathrm{BMI}<24)$, overweight $(24 \leqq$ BMI $<27)$, mild obesity $(27 \leqq B M I<30)$, and moderate obesity $(\mathrm{BMI} \geqq 30)[24]$.

In healthcare, diagnosis codes are used as a tool to group and identify diseases, disorders, symptoms, poisonings, adverse effects of drugs and chemicals, injuries, and other reasons for patient encounters. In the NHIRD, 
diagnosis codes are collected using the ICD-9-CM code (The International Classification of Diseases, Ninth Revision, Clinical Modification). We defined diabetes patients as those who received a diagnosis of diabetes (ICD-9-CM: 250) and at least three outpatient treatments or one hospitalization during the year of the interview survey or within 365 days before or after the survey [25]. We excluded patients with type 1 diabetes, gestational diabetes, neonatal diabetes, or impaired glucose tolerance (ICD-9-CM: 6488, 7751, 7902, 6480). We defined hip fracture as a diagnosis of femoral neck fracture, intertrochanteric fracture, or subtrochanteric fracture (ICD-9-CM: 820.XX) and having received one of the following surgical treatments: partial hip replacement (ICD-9-CM: 81.52), open reduction of fracture with internal fixation of the femur (ICD-9-CM: 79.35), or closed reduction of fracture with internal fixation of the femur (ICD-9-CM: 79.15).

We divided residential areas into seven levels from most urban and to least urban [26]. We calculated the severity of comorbidities based on the CCI revised by Deyo et al. [27] and divided them into groups with scores of $0,1-3$, and $\geqq 4$. We calculated the DCSI based on seven types of diabetes complications (retinopathy, nephropathy, neuropathy, cerebrovascular, cardiovascular, peripheral vascular disease, and metabolic) as classified by Young et al [28] and used different weight scores ( 0 or $\geqq 1$ ) to represent different severities.

In terms of health behaviour, we calculated the weekly energy expenditure through exercise according to the method proposed by Wen et al. [29] using the NHIST. Each type of exercise corresponds to a different Metabolic Equivalent of Task (MET, a unit of exercise intensity) according to the breathing status during exercise. One MET is defined as the oxygen uptake in $\mathrm{ml} / \mathrm{kg} / \mathrm{min}$ when sitting quietly $(3.5 \mathrm{ml} / \mathrm{kg} / \mathrm{min})$. The weekly energy expended in exercise is calculated as follows: MET * frequency of exercises over the past 2 weeks (times) * each exercise duration (hours) * body weight $(\mathrm{kg}) * 7 / 14$. We used the MET to collect and validate the weekly energy expenditure in kilocalories (kcal) for specific exercises, based on which participants were divided into three groups according to the expenditure per week: no exercise, <500 kcal/week, and $\geqq 500 \mathrm{kcal} /$ week.

\section{Statistical analysis}

SAS statistical analysis software version 9.3 (SAS Institute, Cary, NC, U.S.A.) was used for the analysis, and $p$-values $<0.05$ were considered statistically significant. In descriptive statistics, the participants' variables were analysed, including BMI, diabetes status, basic personal characteristics (sex and age), environmental factors (urbanization degree of residential areas), social and economic status (monthly salary), health status (CCI and DCSI), and health behaviour (weekly energy expenditure through exercise). Our aim was to compare the numbers of subjects with hip fractures and percentage distributions. A chi-square test was used to perform analysis to determine the relationship between the variables and incidence of diabetes and level of BMI. A log-rank test was used to determine the relationship with hip fracture incidence.

For the inferential statistical analysis, a Cox proportional hazard model was used to investigate the effects of BMI and diabetes on hip fracture risk after controlling for variables such as personal basic characteristics, environmental factors, social and economic status, health status, and health behaviour. Further, in order to examine whether diabetes has a same effect on risk of hip fracture in those with different BMI, we also examined the interaction relationship between diabetes status and level of BMI on the risk of hip fracture. A stratified analysis was further performed to investigate the effects of diabetes on hip fracture risk in those with different BMI if there was an interaction relationship between diabetes status and level of BMI. Finally, the Cox proportional hazard model was used to investigate the effects of BMI on hip fracture incidence in participants with diabetes.

\section{Results \\ Participant demographics and cox proportional hazard model analysis}

A total of 22,048 subjects were eligible for inclusion in this study (Table 1), of which 3508 had diabetes and 315 had hip fractures. Among the different level of BMI groups, we found that the higher of the BMI, the higher prevalence of diabetes. When the participants had moderate obesity (BMI $\geqq 30$ ), diabetes risk was as high as $33.33 \%$. There was significant difference between diabetes and non-diabetes patients in risk of hip fracture $(p<0.05)$. Additionally, participants with low BMI $(\mathrm{BMI}<18.5)$ showed a higher hip fracture rate $(3.56 \%)$ than other BMI subgroups. There were significant differences between participants with diabetes and those without diabetes in BMI, hip fracture, sex, age, urbanization of residence area, monthly salary, CCI, DCSI and weekly energy expenditure through exercise $(P<0$.05). In Table 2 , there were significant differences in hip fracture incidence between the participants in terms of variables, including BMI, diabetes status, age, monthly salary, CCI, and DCSI $(p<0.05)$.

We also used the Cox proportional hazard model to analyze the effects of BMI and diabetes on hip fracture risk. The results of four models of are shown in Table 3. The first model is the univariate analysis of diabetes and hip fracture with unadjusted results, the second is for diabetes without BMI, the third is for BMI without the diabetes variable, and the final model is for both variables together. In the final model, we found that hip 


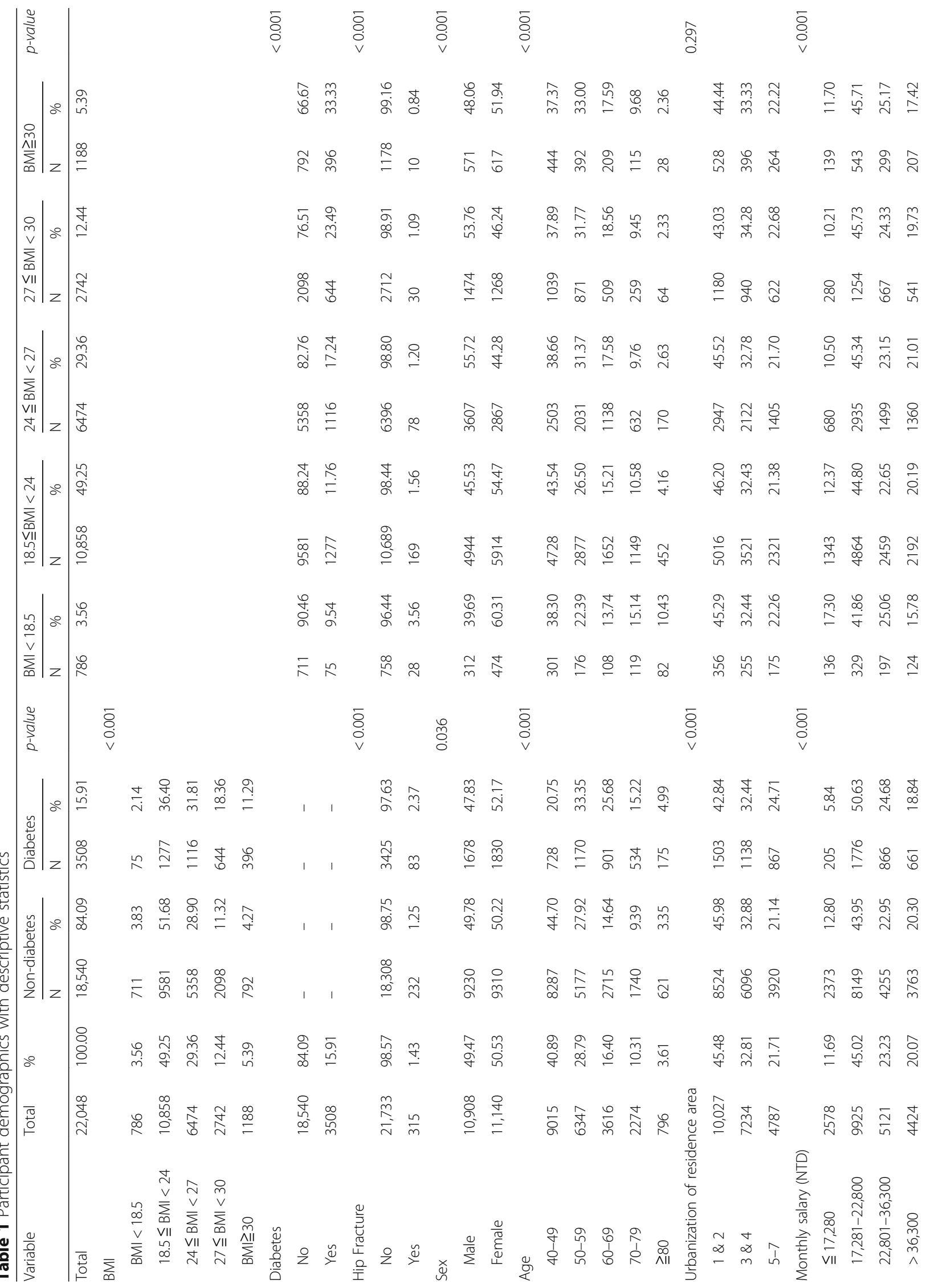




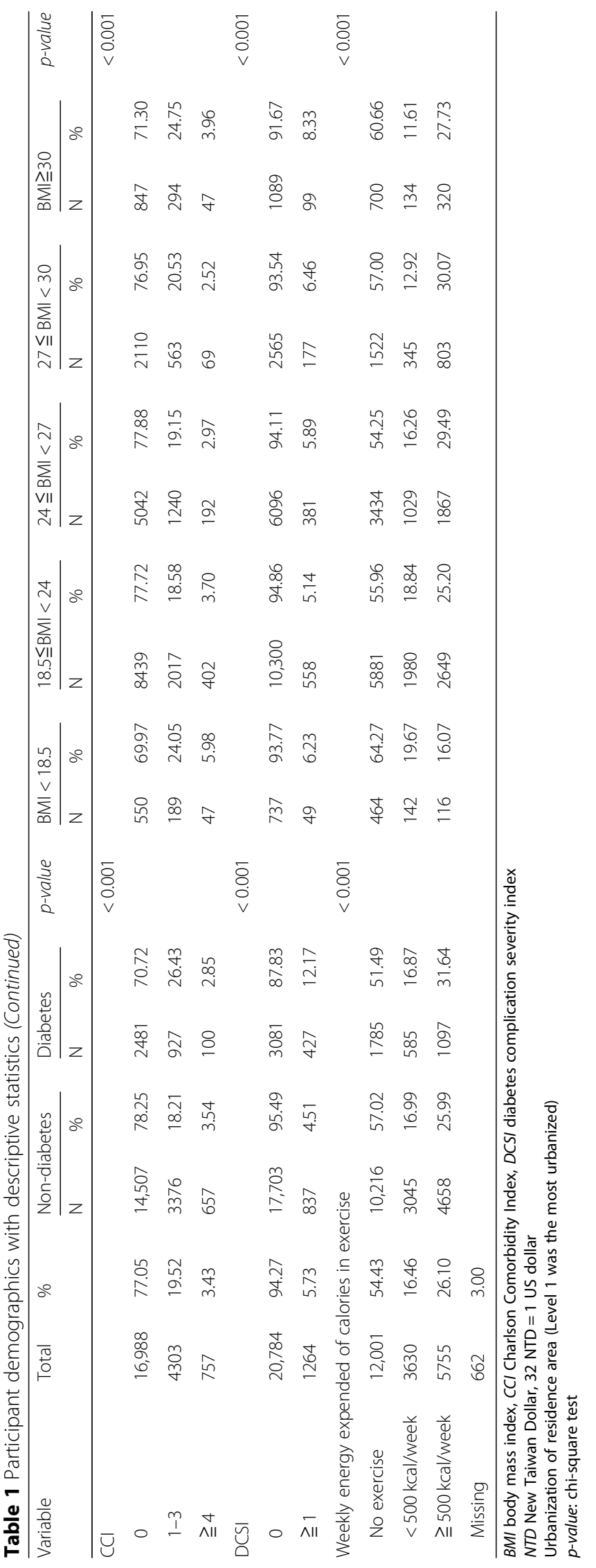


Table 2 Descriptive statistics of participants with or without hip fractures

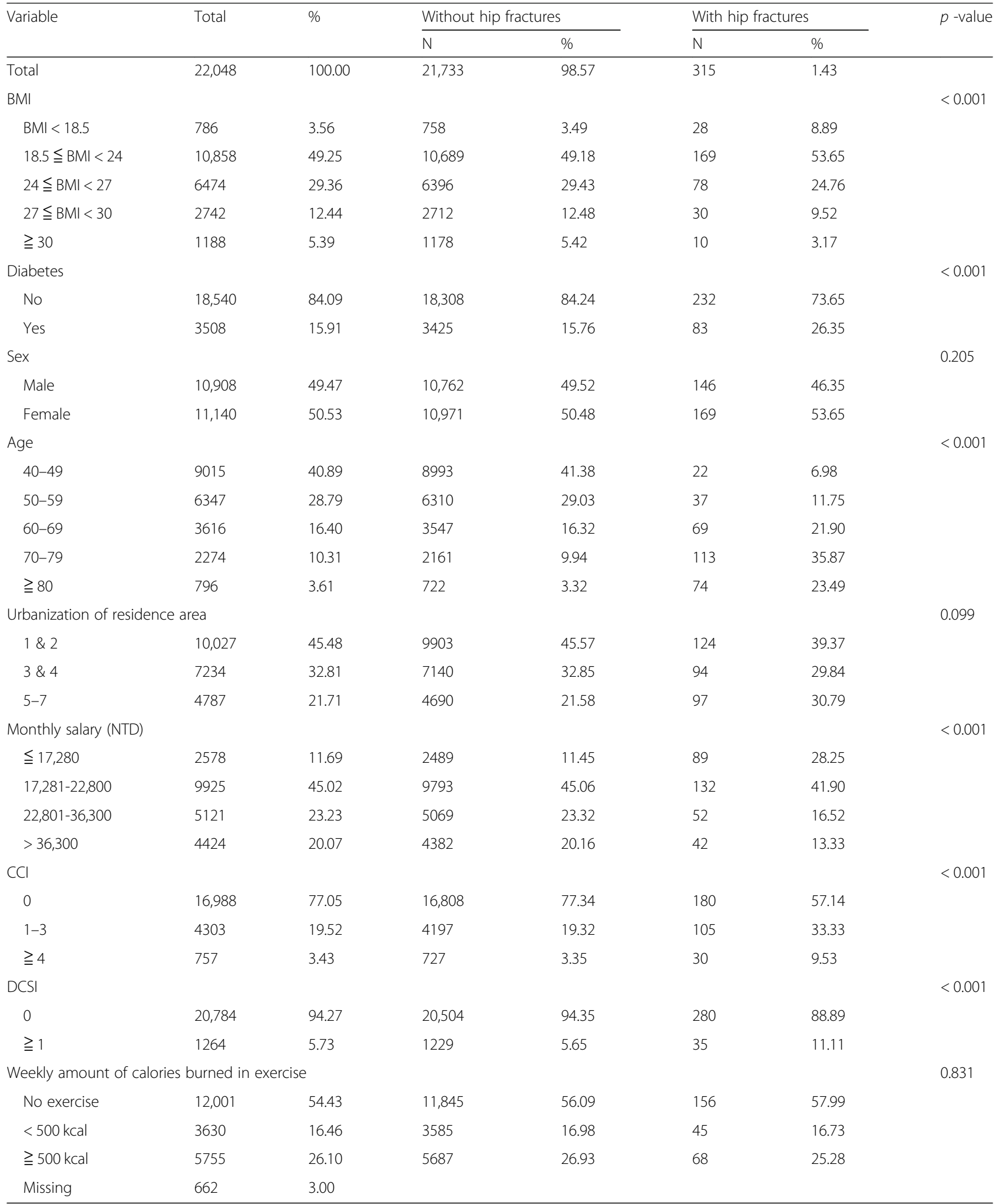

$B M I$ body mass index, $C C I$ Charlson Comorbidity Index, DCSI diabetes complication severity index

NTD New Taiwan Dollar; 32 NTD = 1 US dollar

Urbanization of residence area (Level 1 was the most urbanized)

$p$-value: log-rank test 
Table 3 Cox proportional hazard model analysis of hip fracture risk in all participants

\begin{tabular}{|c|c|c|c|c|c|c|c|c|c|c|c|c|}
\hline \multirow[t]{2}{*}{ Variables } & \multirow[t]{2}{*}{ Unadjusted HR } & \multirow[t]{2}{*}{ p-value } & \multicolumn{3}{|c|}{ Diabetes without BMI } & \multicolumn{3}{|c|}{ BMI without diabetes } & \multicolumn{4}{|c|}{ Diabetes and BMI together } \\
\hline & & & \multirow[t]{2}{*}{ Adjusted HR } & \multicolumn{2}{|l|}{$95 \% \mathrm{Cl}$} & \multirow[t]{2}{*}{ Adjusted HR } & \multicolumn{2}{|l|}{$95 \% \mathrm{Cl}$} & \multirow[t]{2}{*}{ Adjusted HR } & \multicolumn{2}{|l|}{$95 \% \mathrm{Cl}$} & \multirow[t]{2}{*}{$\overline{p \text {-value }}$} \\
\hline \multicolumn{9}{|l|}{ Diabetes } & & & & \\
\hline \multicolumn{13}{|l|}{ No (ref.) } \\
\hline Yes & 2.04 & $<0.001$ & 1.54 & 1.18 & 2.00 & - & - & - & 1.64 & 1.30 & 2.15 & $<0.001$ \\
\hline \multicolumn{13}{|l|}{ BMI } \\
\hline $18.5 \leqq \mathrm{BMI}<24$ (ref.) & - & - & - & - & - & & & & & & & \\
\hline $\mathrm{BMI}<18.5$ & 2.58 & $<0.001$ & - & - & - & 1.71 & 1.14 & 2.56 & 1.75 & 1.17 & 2.61 & 0.007 \\
\hline $24 \leqq \mathrm{BMI}<27$ & 0.78 & 0.072 & - & - & - & 0.86 & 0.66 & 1.13 & 0.84 & 0.64 & 1.10 & 0.205 \\
\hline $27 \leqq \mathrm{BMI}<30$ & 0.72 & 0.098 & - & - & - & 0.75 & 0.51 & 1.11 & 0.70 & 0.48 & 1.04 & 0.076 \\
\hline $\mathrm{BMI} \geqq 30$ & 0.60 & 0.111 & - & - & - & 0.61 & 0.32 & 1.16 & 0.55 & 0.29 & 1.05 & 0.072 \\
\hline \multicolumn{13}{|l|}{ Sex } \\
\hline \multicolumn{13}{|l|}{ Male (ref.) } \\
\hline Female & 1.15 & 0.206 & 1.28 & 1.02 & 1.60 & 1.30 & 1.04 & 1.63 & 1.29 & 1.03 & 1.62 & 0.027 \\
\hline \multicolumn{13}{|l|}{ Age } \\
\hline \multicolumn{13}{|l|}{ 40-49 (ref.) } \\
\hline 50-59 & 2.66 & 0.000 & 2.47 & 1.45 & 4.19 & 2.63 & 1.55 & 4.46 & 2.50 & 1.47 & 4.25 & 0.001 \\
\hline $60-69$ & 9.12 & $<0.001$ & 7.81 & 4.79 & 12.72 & 8.62 & 5.31 & 14.01 & 7.87 & 4.83 & 12.83 & $<0.001$ \\
\hline 70-79 & 27.67 & $<0.001$ & 23.19 & 14.41 & 37.33 & 24.86 & 15.47 & 39.94 & 22.68 & 14.08 & 36.52 & $<0.001$ \\
\hline$\geqq 80$ & 75.60 & $<0.001$ & 56.01 & 33.99 & 92.29 & 58.24 & 35.39 & 95.87 & 52.16 & 31.60 & 86.09 & $<0.001$ \\
\hline \multicolumn{13}{|c|}{ Urbanization of residence area } \\
\hline \multicolumn{13}{|l|}{$1 \& 2$ (ref.) } \\
\hline $3 \& 4$ & 0.96 & 0.787 & 0.97 & 0.74 & 1.28 & 0.96 & 0.73 & 1.26 & 0.96 & 0.73 & 1.26 & 0.768 \\
\hline $5-7$ & 1.28 & 0.073 & 1.21 & 0.91 & 1.60 & 1.17 & 0.88 & 1.56 & 1.18 & 0.89 & 1.57 & 0.251 \\
\hline \multicolumn{13}{|l|}{ Monthly salary (NTD) } \\
\hline$\leqq 17,280$ (ref.) & & & & & & & & & & & & \\
\hline $17,281-22,800$ & 0.36 & $<0.001$ & 0.71 & 0.52 & 0.97 & 0.78 & 0.57 & 1.05 & 0.70 & 0.52 & 0.96 & 0.025 \\
\hline $22,801-36,300$ & 0.34 & $<0.001$ & 0.85 & 0.58 & 1.23 & 0.93 & 0.64 & 1.35 & 0.84 & 0.58 & 1.22 & 0.349 \\
\hline$>36,300$ & 0.27 & $<0.001$ & 0.87 & 0.58 & 1.31 & 0.98 & 0.66 & 1.45 & 0.86 & 0.58 & 1.29 & 0.471 \\
\hline $\mathrm{CCl}$ & & & & & & & & & & & & \\
\hline 0 (ref.) & & & & & & & & & & & & \\
\hline $1-3$ & 2.55 & $<0.001$ & 1.58 & 1.23 & 2.04 & 1.56 & 1.22 & 2.01 & 1.58 & 1.23 & 2.04 & 0.000 \\
\hline$\geqq 4$ & 5.44 & $<0.001$ & 2.58 & 1.73 & 3.86 & 2.46 & 1.65 & 3.66 & 2.64 & 1.77 & 3.95 & $<0.001$ \\
\hline DCSI & & & & & & & & & & & & \\
\hline 0 (ref.) & & & & & & & & & & & & \\
\hline$\geqq 1$ & 2.55 & $<0.001$ & 1.34 & 0.93 & 1.93 & 1.43 & 0.99 & 2.07 & 1.35 & 0.93 & 1.95 & 0.112 \\
\hline Weekly energy expend & ed of calories in ex & xercise & & & & & & & & & & \\
\hline No exercise (ref.) & & & & & & & & & & & & \\
\hline$<500 \mathrm{kcal} /$ week & 0.78 & 0.129 & 0.80 & 0.57 & 1.11 & 0.81 & 0.58 & 1.13 & 0.80 & 0.57 & 1.11 & 0.181 \\
\hline$\geqq 500 \mathrm{kcal} /$ week & 0.75 & 0.038 & 0.65 & 0.49 & 0.86 & 0.68 & 0.51 & 0.91 & 0.67 & 0.50 & 0.89 & 0.006 \\
\hline
\end{tabular}

$B M I$ body mass index, $\mathrm{CCl}$ Charlson Comorbidity Index, DCSI diabetes complication severity index, $\mathrm{HR}$ hazard ratio, $\mathrm{Cl}$ confidence interval NTD New Taiwan Dollar; 32 NTD $=1$ US dollar

Urbanization of residence area (overall 7 levels; Level 1 was the most urbanized)

fracture risk in diabetes patients was 1.64 times the risk in non-diabetes patients (95\% CI: $1.30-2.15, p<0.05$ ). Patients with low BMI showed a higher hip fracture risk
(Adjusted hazards ratio [Adj. HR]: 1.75, 95\% CI: 1.17-2.61) than those with normal BMI (reference). Additionally, patients who were overweight, mildly obese, or moderately 
Table 4 Stratified analysis of the relative risk of hip fracture between diabetes and non-diabetes patients in terms of BMI

\begin{tabular}{|c|c|c|c|c|c|c|c|c|c|c|}
\hline \multirow[t]{3}{*}{ Variables } & \multicolumn{3}{|c|}{ Diabetes patients } & \multicolumn{3}{|c|}{ Non-diabetes patients } & \multirow{3}{*}{\multicolumn{2}{|c|}{$\begin{array}{l}\text { Adj. HR (diabetes vs. } \\
\text { non-diabetic) }\end{array}$}} & \multirow[t]{3}{*}{$95 \% \mathrm{Cl}$} & \multirow[t]{3}{*}{$p$-value } \\
\hline & \multirow[t]{2}{*}{$\mathrm{N}$} & \multicolumn{2}{|c|}{ Hip fractures } & \multirow[t]{2}{*}{$\mathrm{N}$} & \multicolumn{2}{|c|}{ Hip fractures (N) (\%) } & & & & \\
\hline & & $(\mathrm{N})$ & $(\%)$ & & $(\mathrm{N})$ & $(\%)$ & & & & \\
\hline Sum & 3508 & 83 & 2.37 & 18,540 & 232 & 1.25 & 1.64 & 1.30 & 2.15 & $<0.001$ \\
\hline \multicolumn{11}{|l|}{ BMI } \\
\hline $\mathrm{BMI}<18.5$ & 75 & 6 & 8.00 & 711 & 22 & 3.09 & 2.47 & 0.90 & 6.74 & 0.079 \\
\hline $18.5 \leqq \mathrm{BMI}<24$ & 1277 & 46 & 3.60 & 9581 & 123 & 1.28 & 2.13 & 1.48 & 3.06 & $<0.001$ \\
\hline $24 \leqq \mathrm{BMl}<27$ & 1116 & 17 & 1.52 & 5358 & 61 & 1.14 & 1.01 & 0.57 & 1.75 & 0.996 \\
\hline $27 \leqq B M I<30$ & 644 & 9 & 1.40 & 2098 & 21 & 1.00 & 1.24 & 0.54 & 2.86 & 0.618 \\
\hline $\mathrm{BMI} \geqq 30$ & 396 & 5 & 1.26 & 792 & 5 & 0.63 & 2.37 & 0.57 & 9.84 & 0.236 \\
\hline
\end{tabular}

Note: Cox proportional hazards model was used and controlled for sex, age, urbanization of residence area, monthly salary, CCl, DCSI and weekly energy expenditure through exercise

obese had lower hip fracture risk than patients with normal BMI, but the differences were not statistically significant $(p>0.05)$. Hip fracture risk in female patients was 1.29 times that in male patients (95\% CI: 1.03-1.62, $p=0.027$ ). Compared with a reference group (aged 40-49 years), older patients showed a higher hip fracture risk $(p<0.05)$ : among subjects $\geqq 80$ years old, hip fracture risk was as high as 52.16 times the baseline risk. Separately, participants with higher CCI scores showed a higher hip fracture risk than the reference group $(\mathrm{CCI}=0)$, and hip fracture risk in those who expended $\geqq 500 \mathrm{kcal} /$ week in exercise was 0.67 times lower than in those who did not exercise (95\% CI: $0.50-0.89$ ).

We also tested the interaction relationship between diabetes status and level of BMI in risk of hip fracture. The result revealed that there was a significant interaction effect between diabetes status and level of BMI in hip fracture risk $(p=0.001)$.

\section{Stratified analysis of the effects of BMI and relative factors on hip fracture risk in diabetes patients}

We used stratified analysis to examine the relative risk of hip fracture between diabetes and non-diabetes patients at different level of BMI (Table 4). After relevant variables were controlled in Cox proportional hazard model, hip fracture risk in diabetes patients was greater than that in non-diabetes patients regardless of BMI. Among the five BMI groups, compared with non-diabetes patients, only diabetes patients with a normal BMI $(18.5 \leqq \mathrm{BMI}<24)$ showed a statistically significant difference in hip fracture risk (Adj. HR: 2.13, 95\% CI: $1.48-3.06, P<0.05)$. It means that diabetes increases risk of hip fracture but the magnitude of risk varies with the BMI level.

\section{Analysis of the effects of relative factors on hip fracture risk in diabetes patients}

A Cox proportional hazard model was used to analyze diabetes patients (Table 5 \& Fig. 1). Compared with a reference group (normal $\mathrm{BMI}, 18.5 \leqq \mathrm{BMI}<24$ ), those with overweight $(24 \leqq B M I<27)$ or obesity $(\mathrm{BMI} \geqq 27)$ showed a lower hip fracture risk (Adj. HR: 0.49 vs. 0.42, $p<0.05$ ). Compared with the reference group (aged 40-49 years), older patients showed a higher hip fracture risk, but statistically significant differences were only observed in patients $\geqq 60$ years old $(p<0.05)$. Among diabetes patients, those with higher CCI or DCSI scores were associated with a higher hip fracture risk. As the weekly energy expended in exercise increased in diabetes patients, hip fracture risk decreased compared with diabetes patients without exercise. In particular, when the weekly energy expenditure was $\geqq 500 \mathrm{kcal} /$ week, hip fracture risk in diabetes patients was significantly decreased to 0.54 times (95\% CI: 0.31-0.94, $p<0.05$ ).

\section{Discussion}

This study is the first to use nationwide survey data in combination with data from the NHIRD to investigate the effects of BMI, diabetes, and relative factors on hip fracture risk. According to findings from previous studies, multiple complex factors in diabetes patients may cause abnormal bone metabolism and increase fracture incidence and subsequent complications [5, 6]. After controlling for other variables (including BMI), we also found that hip fracture risk in patients with type 2 diabetes was 1.64 times that in non-diabetes patients (Table 3), which was consistent with previous studies $[4,5,30]$.

The analysis results in Table 3 show that all participants with low BMI $(<18.5)$ had a higher hip fracture risk (Adj. HR: 1.75, 95\% CI: 1.17-2.61, $p=0.007$ ) than those with normal BMI $(18.5 \leqq \mathrm{BMI}<24)$. De Laet et al. [14] used a meta-analysis approach to study nearly 60,000 men and women from 12 cohorts of both Asian and Western participants. They found that low BMI conferred a significant risk for all types of fractures in both Asian and Western populations. They found that low BMI is an important risk factor for hip fractures. There were similar findings in the diabetes patients 
Table 5 Analysis of the effect of BMI on hip fracture risk in diabetes patients

\begin{tabular}{|c|c|c|c|c|c|c|}
\hline \multirow{2}{*}{$\begin{array}{l}\text { Variables } \\
\mathrm{BMI}\end{array}$} & \multirow[t]{2}{*}{ Unadjusted HR } & \multirow[t]{2}{*}{$p$-value } & \multirow[t]{2}{*}{ Adjusted HR } & \multicolumn{2}{|c|}{$95 \% \mathrm{Cl}$} & \multirow[t]{2}{*}{$p$-value } \\
\hline & & & & & & \\
\hline \multicolumn{7}{|c|}{$18.5 \leqq \mathrm{BMI}<24$ (ref.) } \\
\hline $\mathrm{BMI}<18.5$ & 2.54 & 0.032 & 1.78 & 0.75 & 4.26 & 0.193 \\
\hline $24 \leqq \mathrm{BMI}<27$ & 0.42 & 0.002 & 0.49 & 0.28 & 0.85 & 0.012 \\
\hline $\mathrm{BMI} \geqq 27$ & 0.38 & 0.001 & 0.42 & 0.23 & 0.78 & 0.006 \\
\hline \multicolumn{7}{|l|}{ Sex } \\
\hline \multicolumn{7}{|l|}{ Male (ref.) } \\
\hline Female & 1.34 & 0.189 & 1.33 & 0.85 & 2.08 & 0.215 \\
\hline \multicolumn{7}{|l|}{ Age } \\
\hline \multicolumn{7}{|l|}{ 40-49 (ref.) } \\
\hline $50-59$ & 1.81 & 0.258 & 1.73 & 0.62 & 4.88 & 0.298 \\
\hline $60-69$ & 5.16 & 0.001 & 4.67 & 1.78 & 12.25 & 0.002 \\
\hline 70-79 & 11.32 & $<0.001$ & 10.20 & 3.82 & 27.27 & $<0.001$ \\
\hline$\geqq 80$ & 23.02 & $<0.001$ & 16.97 & 5.94 & 48.43 & $<0.001$ \\
\hline \multicolumn{7}{|c|}{ Urbanization of residence area } \\
\hline \multicolumn{7}{|l|}{$1 \& 2$ (ref.) } \\
\hline $3 \& 4$ & 0.76 & 0.289 & 0.79 & 0.46 & 1.36 & 0.402 \\
\hline $5-7$ & 0.81 & 0.425 & 0.84 & 0.47 & 1.47 & 0.535 \\
\hline \multicolumn{7}{|l|}{ Monthly salary (NTD) } \\
\hline \multicolumn{7}{|l|}{$\leqq 17,280$ (ref.) } \\
\hline $17,281-22,800$ & 0.55 & 0.122 & 0.74 & 0.34 & 1.63 & 0.457 \\
\hline $22,801-36,300$ & 0.78 & 0.548 & 1.09 & 0.47 & 2.51 & 0.837 \\
\hline$>36,300$ & 0.42 & 0.058 & 0.63 & 0.25 & 1.61 & 0.338 \\
\hline \multicolumn{7}{|l|}{$\mathrm{CCl}$} \\
\hline \multicolumn{7}{|l|}{0 (ref.) } \\
\hline $1-3$ & 2.17 & 0.001 & 1.51 & 0.92 & 2.47 & 0.106 \\
\hline$\geqq 4$ & 5.63 & $<0.001$ & 3.51 & 1.43 & 8.59 & 0.006 \\
\hline \multicolumn{7}{|l|}{ DCSI } \\
\hline \multicolumn{7}{|l|}{0 (ref.) } \\
\hline$\geqq 1$ & 2.70 & $<0.001$ & 1.68 & 0.94 & 3.03 & 0.082 \\
\hline \multicolumn{7}{|c|}{ Weekly energy expended of calories in exercise } \\
\hline \multicolumn{7}{|l|}{ No exercise (ref.) } \\
\hline$<500 \mathrm{kcal} /$ week & 0.73 & 0.314 & 0.65 & 0.35 & 1.22 & 0.178 \\
\hline$\geqq 500 \mathrm{kcal} /$ week & 0.59 & 0.050 & 0.54 & 0.31 & 0.94 & 0.029 \\
\hline
\end{tabular}

BMI body mass index, CCI Charlson Comorbidity Index, DCSI diabetes complication severity index;

$H R$ hazard ratio, $\mathrm{Cl}$ confidence interval

NTD New Taiwan Dollar, 32 NTD = 1 US dollar

Urbanization of residence area (overall 7 levels; Level 1 was the most urbanized)

group (Table 5), but the result was not significant (Adj. HR: 1.78 , 95\% CI: 0.75-4.26, $p=0.193$ ). After further analysis, only 83 diabetes patients had hip fractures. In addition, it was found that only six individuals had hip fractures among 75 diabetes patients with low BMI $(\mathrm{BMI}<18.5)$. We believe that if the number of subjects was increased or if the subjects were observed for a longer period of time, the statistical results in variables could perhaps become significant.

To understand whether hip fracture risk of diabetes was the same in patients with different BMI, stratified analysis was performed (Table 4). Analysis results showed that diabetes patients had a higher hip fracture risk than non-diabetes patients in all MBI subgroups, 


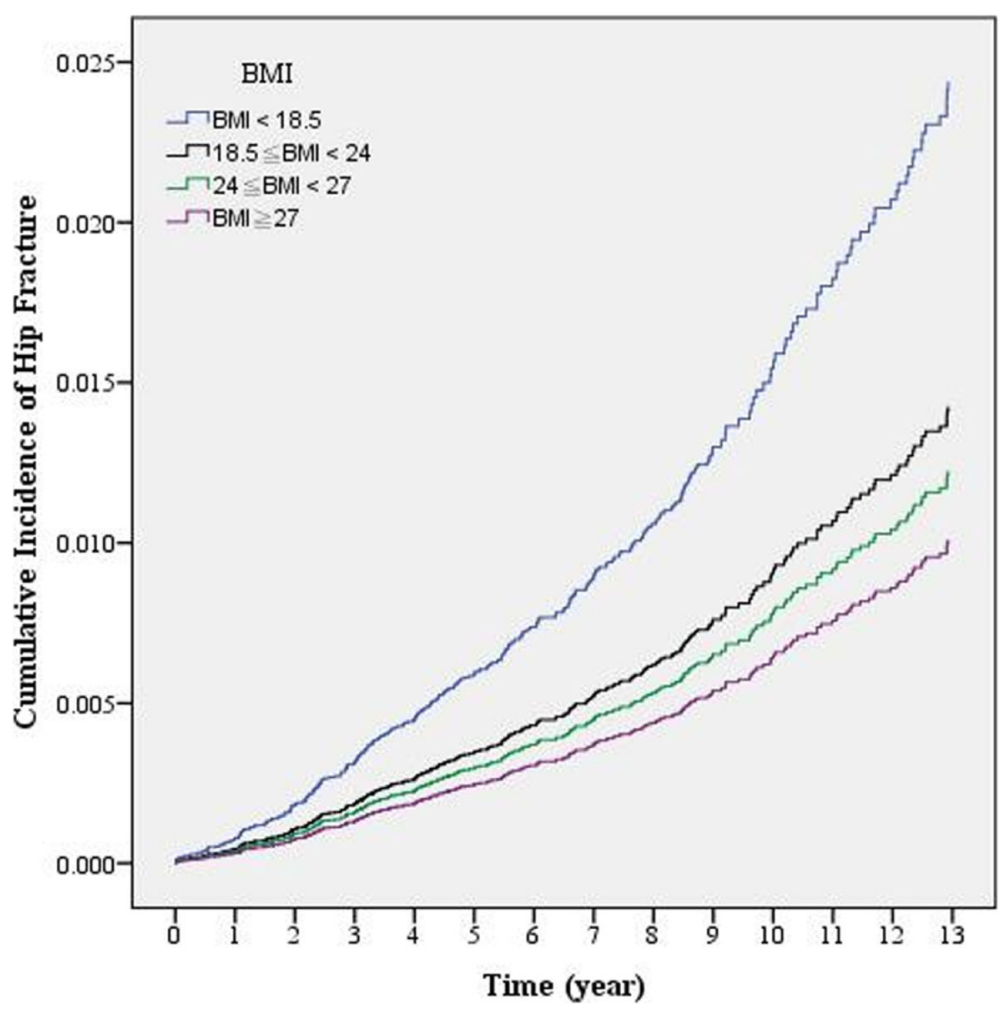

Fig. 1 Comparisons of hip fracture risk among different BMl groups in patients with diabetes (After controlling for sex, age, urbanization of residence area, monthly salary, $\mathrm{CCl}, \mathrm{DCSI}$ and weekly energy expenditure through exercise)

but only those with a normal BMI showed significant differences (Adj. HR: 2.13, 95\% CI: 1.48-3.06). It reflected the impact of diabetes on risk of hip fracture were not constant in people with different BMIs. The effect of diabetes on increasing hip fracture risk was more significant in those with lower BMI. The results indicated that diabetes as a risk factor for hip fracture was not independent of BMI, which was a novel finding.

Many studies have pointed out that overweight and obesity can increase the incidence of metabolic diseases $[11,12]$. The similar result was also found in Table 1. Participant with a higher BMI had higher risks in type 2 diabetes. However, as shown in Table 5 and Fig. 1, we found that diabetes patients with high BMI $(24 \leqq B M I<27)$ or obesity (BMI $\geqq 27)$ showed a lower hip fracture risk (Adj. HR: 0.49 vs. $0.42, p<0.05)$ compared with the reference group (normal BMI). This is consistent with the report by Johansson et al [16], who analysed $>300,000$ women from more than 25 countries and found that $87 \%$ of hip fractures occurred in those without obesity (defined as $\mathrm{BMI} \geqq 30 \mathrm{~kg} / \mathrm{m}^{2}$ ). Furthermore, a relatively high BMI decreased the fracture risk in these women. The same result was found in all participants in which high BMI was protective against hip fracture, but there was no significant difference from the reference group (normal BMI, Table 3).However, high BMI is hardly a public health strategy that should be advocated, given concerns about cardiovascular disease in this population.

\section{Limitations}

There were several limitations to our analyses. Data from the NHIRD were used for the analysis, so not all health behaviours and other factors were included in the analysis, such as eating habits, body composition/muscle mass, muscle function/sarcopenia, and history of falls history. Moreover, the duration of diabetes in all subjects and their blood glucose control status were not known.

\section{Conclusion}

In this study, we found that diabetes increased hip fracture risk (HR: 1.64), and both diabetes and BMI had an interaction on risk of hip fracture $(P=0.001)$. The findings from this study revealed the following: (1) those with diabetes sustain more hip fractures, (2) low BMI was a risk factor for hip fracture, (3) The effect of diabetes on increasing hip fracture risk was more significant in those with lower BMI, and (4) physical exercise was important in preventing hip fractures, including among patients with diabetes.

It was not even clear whether any exercise was a significant protective factor in individuals with diabetes alone, or whether the result was driven by the general population. However, we found that energy expenditure 
through exercise $\geqq 500 \mathrm{kcal} /$ week per week could effectively decrease hip fracture risk in the general population and in those with diabetes. Regardless of BMI or diabetes status, exercise helps prevent falls and hip fractures and was therefore especially important for diabetes patients. Hence, health education for diabetes on managing body weight and increasing the amount of exercise could effectively prevent hip fractures. The results of this study could be used as a reference for health education and health promotion measures for diabetes patients.

\section{Abbreviations}

Adj. HR: Adjusted hazards ratio; BMI: Body mass index; CCl: Charlson Comorbidity Index; Cl: Confidence interval; DCSI: Diabetes complication severity index; ICD-9-CM: The International Classification of Diseases, Ninth Revision, Clinical Modification; MET: Metabolic Equivalent of Task; NHIRD: National Health Insurance Research Database; NHIST: National Health Interview Survey in Taiwan; NTD: New Taiwan Dollar; RR: Relative risk; US: United States; WHO: World Health Organization

\section{Acknowledgments}

This study was supported by the grants (CMU104-S-27, DOH10541) from China Medical University as well as Ministry of Health and Welfare, Taiwan. We are grateful for use of the National Health Insurance Research Database and the National Health Interview Survey in Taiwan. R.O.C.

\section{Funding}

This study was supported by the grants (CMU104-S-27, DOH10541) from China Medical University as well as Ministry of Health and Welfare, Taiwan.

\section{Authors' contributions}

$\mathrm{HLH}$ and WCT drafted the manuscript. WCT, YFH and PTK designed the study. CCP, LTC, MCC and CYK collected data. HLH, PTK and WCT were responsible for study conceptualization and developing the analytical plan. All authors read and approved the final manuscript.

\section{Ethics approval and consent to participate}

Data are available from the Science Center, the Ministry of Health and Welfare (MOHW), Taiwan. This study obtained the databases published and managed by the MOHW. All researchers are allowed to use the databases for their interested studies. Before using the databases for research, all studies should get the IRB permission. The institutional review board of China Medical University approved this study (IRB No.: CMUH 103-REC3-109).

\section{Consent for publication}

Not applicable.

\section{Competing interests}

The authors declare that they have no competing interests.

\section{Publisher's Note}

Springer Nature remains neutral with regard to jurisdictional claims in published maps and institutional affiliations.

\footnotetext{
Author details

'Department of Social Work, Toko University, Chiayi County, Taiwan, Republic of China. ${ }^{2}$ Department of Health Services Administration, China Medical University, 91, Hsueh-Shih Road, Taichung 40402, Taiwan, Republic of China. ${ }^{3}$ Department of Urology, Ministry of Health and Welfare, Hengchun Tourism Hospital, Hengchun, Taiwan, Republic of China. ${ }^{4}$ Department of Orthopedics, Ministry of Health and Welfare, Hengchun Tourism Hospital, Hengchun, Taiwan, Republic of China. ${ }^{5}$ Department of Nursing, Ministry of Health and Welfare, Hengchun Tourism Hospital, Hengchun, Taiwan, Republic of China. ${ }^{6}$ Department of Healthcare Administration, Asia University, Taichung, Taiwan, Republic of China. ${ }^{7}$ Department of Medical Research, China Medical University Hospital, China Medical University, Taichung, Taiwan, Republic of China.
}

Received: 1 March 2018 Accepted: 19 November 2018

Published online: 29 November 2018

\section{References}

1. Kannus P, Parkkari J, Sievänen H, Heinonen A, Vuori I, Järvinen M. Epidemiology of hip fractures. Bone. 1996;18(1):S57-63.

2. Katsoulis M, Benetou V, Karapetyan T, Feskanich D, Grodstein F, PetterssonKymmer U, Eriksson S, Wilsgaard T, Jørgensen L, Ahmed L. Excess mortality after hip fracture in elderly persons from Europe and the USA: the CHANCES project. J Intern Med. 2017;281(3):300-10.

3. Jürisson $M$, Pisarev $H$, Kanis J, Borgström F, Svedbom A, Kallikorm R, Lember M, Uusküla A. Quality of life, resource use, and costs related to hip fracture in Estonia. Osteoporos Int. 2016;27(8):2555-66.

4. Dhaliwal R, Cibula D, Ghosh C, Weinstock R, Moses A. Bone quality assessment in type 2 diabetes mellitus. Osteoporos Int. 2014;25(7):1969-73.

5. Janghorbani M, Van Dam RM, Willett WC, Hu FB. Systematic review of type 1 and type 2 diabetes mellitus and risk of fracture. Am J Epidemiol. 2007; 166(5):495-505.

6. Lin Y-K, Chen C-P, Tsai W-C, Chiao Y-C, Lin BY-J. Cost-effectiveness of clinical pathway in coronary artery bypass surgery. J Med Syst. 2011;35(2):203-13.

7. Koh W-P, Wang R, Ang L-W, Heng D, Yuan J-M, Mimi CY. Diabetes and risk of hip fracture in the Singapore Chinese health study. Diabetes Care. 2010; 33(8):1766-70

8. Dai Z, Ang L-W, Yuan J-M, Koh W-P. Association between change in body weight after midlife and risk of hip fracture - the Singapore Chinese health study. Osteoporos Int. 2015;26(7):1939-47.

9. World Health Organization: Health topics: Body mass index - BMI. Available: http://www.euro.who.int/en/health-topics/disease-prevention/nutrition/ahealthy-lifestyle/body-mass-index-bmi. Accessed 10 Mar 2018.

10. Cawley J, Meyerhoefer C, Biener A, Hammer M, Wintfeld N. Savings in medical expenditures associated with reductions in body mass index among US adults with obesity, by diabetes status. Pharmacoeconomics. 2015;33(7):707-22.

11. Mokdad AH, Ford ES, Bowman BA, Dietz WH, Vinicor F, Bales VS, Marks JS. Prevalence of obesity, diabetes, and obesity-related health risk factors, 2001. Jama. 2003;289(1):76-9.

12. Field AE, Coakley EH, Must A, Spadano JL, Laird N, Dietz WH, Rimm E, Colditz GA. Impact of overweight on the risk of developing common chronic diseases during a 10-year period. Arch Intern Med. 2001;161(13):1581-6.

13. Søgaard AJ, Holvik K, Omsland TK, Tell GS, Dahl C, Schei B, Falch JA, Eisman JA, Meyer HE. Abdominal obesity increases the risk of hip fracture. A population-based study of 43000 women and men aged 60-79 years followed for 8 years. Cohort of $\mathrm{N}$ orway. J Intern Med. 2015;277(3):306-17.

14. De Laet $C$, Kanis J, Odén A, Johanson H, Johnell O, Delmas P, Eisman J, Kroger H, Fujiwara S, Garnero P. Body mass index as a predictor of fracture risk: a meta-analysis. Osteoporos Int. 2005;16(11):1330-8.

15. Aurégan J-C, Frison A, Bégué T, Hannouche D, Bosser C, Bensidhoum M, Hoc T. Contra-lateral hip fracture in the elderly: are decreased body mass index and skin thickness predictive factors? Int Orthop. 2017:41(2):247-52.

16. Johansson H, Kanis JA, Odén A, McCloskey E, Chapurlat RD, Christiansen C, Cummings SR, Diez-Perez A, Eisman JA, Fujiwara S. A meta-analysis of the association of fracture risk and body mass index in women. J Bone Miner Res. 2014;29(1):223-33.

17. Compston JE, Watts NB, Chapurlat R, Cooper C, Boonen S, Greenspan S, Pfeilschifter J, Silverman S, Díez-Pérez A, Lindsay R. Obesity is not protective against fracture in postmenopausal women: GLOW. Am J Med. 2011; 124(11):1043-50.

18. Health Promotion Administration, Ministry of Health and Welfare. National Health Interview Survey 2016. Available: http://nhis.nhri.org.tw/2005nhis.html. Accessed 10 Sept 2017.

19. National Health insurance Administration, Ministry of Health and Welfare. Statistics \& Surveys, 2013. Available: http://www.nhi.gov.tw. Accessed 20 Dec 2017.

20. Cheng T-M. Taiwan's new national health insurance program: genesis and experience so far. Health Aff. 2003:22(3):61-76.

21. J-FR L, Hsiao WC. Does universal health insurance make health care unaffordable? Lessons from Taiwan. Health Aff (Millwood). 2003:22(3):77-88.

22. Huang H-L, Pan C-C, Wang S-M, Kung P-T, Chou W-Y, Tsai W-C. The incidence risk of type 2 diabetes mellitus in female nurses: a nationwide matched cohort study. BMC Public Health. 2016;16(1):443. 
23. Wu T, Hu H, Lin S, Chie W, Yang R, Liaw C. Trends in hip fracture rates in Taiwan: a nationwide study from 1996 to 2010. Osteoporos Int. 2017;28(2): 653-65.

24. Health Promotion Administration, Ministry of Health and Welfare. Health 99 Education Resource. Available: http://health99.hpa.gov.tw/en/. Accessed 12 Jan 2017.

25. Chang C, Shau W, Jiang Y, Li H, Chang T, H-H Sheu W, Kwok C, Ho L, Chuang $L$. Type 2 diabetes prevalence and incidence among adults in Taiwan during 1999-2004: a national health insurance data set study. Diabet Med. 2010;27(6):636-43.

26. Liu C-Y, Hung Y, Chuang Y, Chen Y, Weng W, Liu J, Liang K. Incorporating development stratification of Taiwan townships into sampling design of large scale health interview survey. J Health Manag. 2006;4(1):1-22.

27. Deyo RA, Cherkin DC, Ciol MA. Adapting a clinical comorbidity index for use with ICD-9-CM administrative databases. J Clin Epidemiol. 1992:45(6):613-9.

28. Young BA, Lin E, Von Korff M, Simon G, Ciechanowski P, Ludman EJ, Everson-Stewart S, Kinder L, Oliver M, Boyko EJ. Diabetes complications severity index and risk of mortality, hospitalization, and healthcare utilization. Am J Manag Care. 2008;14(1):15.

29. Wen C-P, Wai JP-M, Chan H-T, Chan Y-C, Chiang P-H, Cheng T-Y. Evaluating the physical activity policy in Taiwan: comparison of the prevalence of physical activity between Taiwan and the US. Taiwan J Public Health. 2007; 26(5):386-99.

30. Martinez-Laguna D, Tebe C, Javaid M, Nogues X, Arden N, Cooper C, DiezPerez A, Prieto-Alhambra D. Incident type 2 diabetes and hip fracture risk: a population-based matched cohort study. Osteoporos Int. 2015;26(2):827-33.

Ready to submit your research? Choose BMC and benefit from:

- fast, convenient online submission

- thorough peer review by experienced researchers in your field

- rapid publication on acceptance

- support for research data, including large and complex data types

- gold Open Access which fosters wider collaboration and increased citations

- maximum visibility for your research: over $100 \mathrm{M}$ website views per year

At $\mathrm{BMC}$, research is always in progress.

Learn more biomedcentral.com/submissions 